\title{
Extraction and optimization of Mucuna pruriens for dyeing of leather
}

\author{
Natarajan Sundari \\ Sathyabama University, Department of Chemical Engineering, Chennai, Tamil Nadu- 600119, India, \\ e-mail: sundarijun18@gmail.com
}

\begin{abstract}
The present study reports on the leaching of natural pigment from Mucuna pruriens for dyeing of chrome tanned leather samples. The experiments were performed at temperature $\left(30-70^{\circ} \mathrm{C}\right)$, time $(30-90 \mathrm{~min})$, feed to solvent ratio (1:3-1:7) and particle size $(0.25-0.75 \mathrm{~mm})$ using ethanol as solvent. The influence of process variables on percentage yield has been studied and the conditions were optimized using Box-Behnken design. The optimized conditions for intensified extraction was found to occur at a temperature of $60^{\circ} \mathrm{C}$, extraction time of $1 \mathrm{hr}$, for a feed to solvent ratio of $1: 5$ and $0.75 \mathrm{~mm}$ particle size. The $\%$ yield under optimized conditions was found to be $47 \%$. The extraction results were found to agree well with the statistical model $\left(\mathrm{R}^{2}=0.9740\right)$. The colouring ability of extracted dye has been tested on wet blue goat leathers. The dyed leather exhibited a better colour value, strength and fastness properties as inferred from reflectance and visual assessment tests.
\end{abstract}

Keywords: Leaching, Mucuna pruriens, Extraction, Box-Behnken design, dyeing of leather.

\section{INTRODUCTION}

\section{Natural dyes}

Natural dyes, also called as colourants are obtained from different parts of plant materials like root, leaves, fruit, seed and they have several applications in leather, food etc., But due to the discovery of synthetic dyes, the market for natural dyes has got drastically reduced ${ }^{1-4}$. Nowadays synthetic dyes are widely used in leather dyeing process. These dyes are carcinogenic and harmful to the environment. The synthetic dyes are not totally taken up by the leather and the exhausted dye is left as effluent, which may produce environmental hazard ${ }^{5}$. In order to avoid these problems, various treatment methods are in progress, which has its own advantages and disadvantages. Thus, currently there is no perfect method available for removal of these toxic dye effluent wastes. As natural dyes are eco-friendly in nature and biodegradable, extracting dye from natural sources is a good alternative to synthetic dyes whose regular uses had increased the risk of spreading harmful diseases and intolerable effect on both human beings and environment. The process of producing leather and textile products without affecting the ecological balance, human and environmental health, is an important point to be considered $^{6-10}$.

Mucuna pruriens (M. pruriens), which is widely found in bushes and hedges throughout the plains of India, has been chosen as the raw material for the current research. The photograph of $M$. pruriens is shown in Figure 1. Seeds of $M$. pruriens are used as a coffee substitute, in the treatment of Parkinson's disease, as a unani and ayurvedic medicine etc. The extraction of dye from their dark purple coloured flowers has not been focused until now. So an attempt is made to extract pigment from $M$. pruriens.

\section{Optimization of extraction process}

Optimization process involves the development of statistical design of experiments, estimation of coefficients in a mathematical model, predicting the response and checking the adequacy of the model. Response surface methodology (RSM) is a statistical technique used for

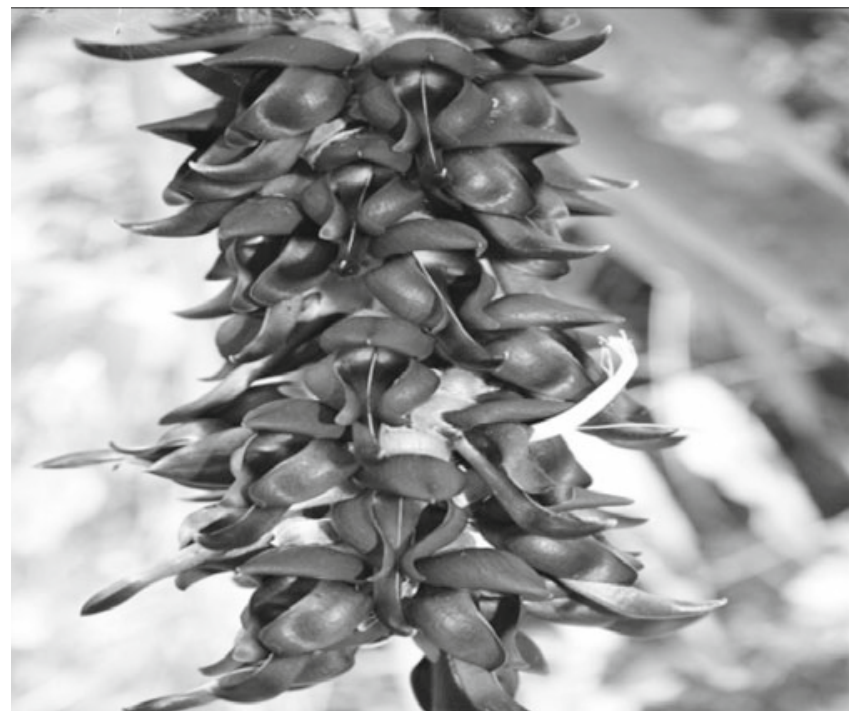

Figure 1. Mucuna pruriens

the development of model, which describes the entire process, interaction between the variables and identification of optimal conditions. Box-Behnken design is a RSM design in which the treatment combinations are at the midpoints of edges of the process space and at the center. One of the advantages of this design is that it does not include all the factors at its extreme lower or higher limit, therefore we can avoid the experiments which may not provide expected results ${ }^{11-13}$. In this study, the influence of various process variables like extraction temperature, time, feed to solvent ratio and size on $\%$ yield of extraction were analyzed by applying Box-Behnken design.

\section{Dyeing of Leather}

The application of pigments extracted from natural source in dyeing of cotton, silk and wool has been tried in several studies ${ }^{14}$. Therefore, this study explores the application of extracted pigments for leather samples. Thus, the main objective of the present study is to develop an eco-friendly method for both extraction of pigment from natural source as well as for application in the leather. In addition to this, the dyeing conditions 
are optimized and dyed leather samples are analyzed by standard methods.

\section{MATERIALS AND METHOD}

\section{Extraction of Natural dye}

The colour bearing M. pruriens samples were collected from Elagiri hills, Vellore, Tamil Nadu. The sample is washed with water to remove the adhering dirt and the extraction was carried out by taking $5 \mathrm{gm}$ of $0.25 \mathrm{~mm}$ sample size in a beaker containing ethanol of 3:1 ratio at $30^{\circ} \mathrm{C}$ for $30 \mathrm{~min}$. The beaker was covered and stirred magnetically to avoid the solvent wastage by evaporation. After extraction, it is filtered and stored under refrigeration. Similar procedure is repeated for sample size varying from 0.25 to $0.75 \mathrm{~mm}$ by taking ethanol to feed ratio ranging from $3: 1$ to $7: 1$ at different temperatures varying from 30 to $70^{\circ} \mathrm{C}$ for $30 \mathrm{~min}$ to $90 \mathrm{~min}$.

The dye samples are then transferred to weighed glass plates and dried in an oven at $45^{\circ} \mathrm{C}$ to evaporate the solvent. It is then cooled and weighed to determine the weight of extract from which the yield was calculated as follows.

$\%$ Yield $=\frac{\text { Amount of Natural dye extract obtained }}{\text { Amount of plant material used }}$

\section{RSM Design}

RSM is a statistical technique, which reduces the number of experiments required to carry out the process, analyze the interaction between various input factors and output called response and optimize the process conditions. In this model, four operating factors namely temperature, time, feed to solvent ratio and size of the particle are chosen as factors. The lower and higher limits for each factors are set for the model (temperature $-30^{\circ} \mathrm{C}$ to $70^{\circ} \mathrm{C}$, time -30 minutes to 90 minutes, feed to solvent ratio $1: 3$ to $1: 7$ and size ranging from $0.25 \mathrm{~mm}$ to $0.75 \mathrm{~mm}$ ). Yield is taken as the response of the system which the output is shown for the particular run. The number of experiments $(\mathrm{N})$ to be conducted for developing the design using Box-Behnken method involves the following formula:

$N=2 f(f-1)+C_{p}$

where, $\mathrm{f}=$ number of factors, $\mathrm{C}_{\mathrm{p}}=$ number of center points.

Thus, it was necessary to conduct 29 experiments for the determination of optimized value. The experimental ranges and levels are given in Table 1.

\section{Dyeing of Leather samples}

The chrome tanned wet blue goat leathers were purchased from Central Leather Research Institute, Chennai. The samples were cut into $3 \mathrm{~cm} \times 3 \mathrm{~cm}$ pieces and the weight of the leather was measured. Re-chroming of leather is done using $0.5 \%$ acetic acid, $5 \%$ basic chromium sulphate, $0.5 \%$ sodium formate and sodium bicarbonate to maintain chrome character of leather with good fullness and softness as it increases the affinity of leather for dyestuffs and ensures level dyeing. After rechroming, the leather piece was soaked in hot water at $35^{\circ} \mathrm{C}-40^{\circ} \mathrm{C}$ for 10 minutes, washed with water followed by addition of $2 \%$ Sodium formate and $1.5 \%$ Sodium bicarbonate and stirred for 30 minutes to neutralize the sample without affecting the stable chrome complex. Dyeing was carried out by shaking the neutralized leather with the extracted dye by taking the concentration of dye and water to be $200 \%$ and $100 \%$ the weight of leather piece in a shaker

Table 1. Experimental design used in RSM studies showing four independent variables and the response \% yield

\begin{tabular}{|c|c|c|c|c|c|c|}
\hline \multirow{2}{*}{ Run } & \multirow{2}{*}{$\begin{array}{c}\text { Temperature } \\
{\left[{ }^{\circ} \mathrm{C}\right]}\end{array}$} & \multirow{2}{*}{$\begin{array}{l}\text { Time } \\
\text { [min] }\end{array}$} & \multirow{2}{*}{ Solvent to feed ratio } & \multirow{2}{*}{$\begin{array}{c}\text { Feed Size } \\
{[\mathrm{mm}]}\end{array}$} & \multicolumn{2}{|c|}{$\%$ Yield } \\
\hline & & & & & Actual & Predicted \\
\hline 1 & 60 & 60 & 6 & 1.25 & 41.00 & 39.58 \\
\hline 2 & 60 & 60 & 5 & 0.75 & 47.00 & 47.00 \\
\hline 3 & 60 & 30 & 5 & 0.25 & 36.00 & 38.00 \\
\hline 4 & 50 & 30 & 5 & 0.75 & 35.00 & 34.58 \\
\hline 5 & 60 & 30 & 6 & 0.75 & 39.00 & 39.08 \\
\hline 6 & 60 & 60 & 5 & 0.75 & 47.00 & 47.00 \\
\hline 7 & 50 & 60 & 4 & 0.75 & 41.00 & 40.00 \\
\hline 8 & 70 & 60 & 5 & 0.25 & 29.00 & 28.42 \\
\hline 9 & 50 & 90 & 5 & 0.75 & 43.00 & 43.08 \\
\hline 10 & 60 & 60 & 5 & 0.75 & 47.00 & 47.00 \\
\hline 11 & 60 & 30 & 5 & 1.25 & 38.00 & 37.50 \\
\hline 12 & 60 & 30 & 4 & 0.75 & 37.00 & 37.42 \\
\hline 13 & 50 & 60 & 5 & 0.25 & 43.00 & 42.08 \\
\hline 14 & 70 & 60 & 5 & 1.25 & 28.00 & 29.42 \\
\hline 15 & 60 & 60 & 4 & 1.25 & 39.00 & 39.42 \\
\hline 16 & 70 & 60 & 6 & 0.75 & 29.00 & 31.00 \\
\hline 17 & 60 & 60 & 6 & 0.25 & 45.00 & 43.08 \\
\hline 18 & 60 & 60 & 4 & 0.25 & 39.00 & 38.92 \\
\hline 19 & 60 & 90 & 4 & 0.75 & 38.00 & 38.42 \\
\hline 20 & 60 & 60 & 5 & 0.75 & 47.00 & 47.00 \\
\hline 21 & 60 & 90 & 5 & 0.25 & 39.00 & 40.50 \\
\hline 22 & 50 & 60 & 6 & 0.75 & 40.00 & 41.17 \\
\hline 23 & 60 & 60 & 5 & 0.75 & 47.00 & 47.00 \\
\hline 24 & 60 & 90 & 6 & 0.75 & 41.00 & 41.08 \\
\hline 25 & 70 & 30 & 5 & 0.75 & 32.00 & 30.42 \\
\hline 26 & 70 & 60 & 4 & 0.75 & 28.00 & 27.83 \\
\hline 27 & 60 & 90 & 5 & 1.25 & 39.00 & 38.00 \\
\hline 28 & 70 & 90 & 5 & 0.75 & 26.00 & 24.92 \\
\hline 29 & 50 & 60 & 5 & 1.25 & 37.00 & 38.08 \\
\hline
\end{tabular}


for 40 minutes. After dyeing, fat liquor (waxing and non-waxing type) constituting $20 \%$ weight of the leather and warm water in the ratio of 1:3 was added to the dyed leather to improve the softness, tensile strength, colour and resistance to chemical attack. Fixing the absorbed colouring agent on to the surface of the dyed leather is essential to withstand with the dye colour for a longer period. So $1 \%$ Formic acid according to the weight of the leather was added for the fixation of colours on the leather pieces.

\section{Visual assessment of leather samples}

The general appearance of leather sample, extent of change in colour due to dyeing, uniformity of dyeing and the strength properties like softness, toughness, fullness are tested and evaluated by three leather experts. The experts rated the leather having the scale 0 to be the lowest and 10 as the highest. These ratings are used to estimate the fitness of dyed leather sample.

\section{Analysis of colour for leather samples}

Colour values of dyed leather samples are determined by colour difference PM-1000 CCD photometer which records the light reflected by the coloured samples and convert the spectrum in to colour coordinate values like 'L', $a$ ' and 'b', thereby describing the colour with numerical values. ' $\mathrm{L}$ ' value extends from 0 to 100 which indicates the lightness or darkness of the sample whereas the positive value of ' $a$ ' indicates a red shade, negative value of 'a' represents green shade, positive value of ' $b$ ' indicates the yellow colour, negative value of ' $b$ ' represents blue shade, 'c' represents the purity and ' $h$ ' the shade of colour.

\section{Estimation of Fastness property}

Dyed leather samples were tested for light fastness after exposing the samples to xenon arc lamp under prescribed conditions for $24 \mathrm{hrs}$ according to IS 6191-1971 ${ }^{\mathbf{1 5}}$. These samples are then assessed and rated by Grey scale assessment as follows: 1. poor, 2. fair, 3. fairly good, 4. good excellent.

Table 2. ANOVA for Response Surface Quadratic Model

\section{RESULTS AND DISCUSSION}

In this study, attempt has been made to optimize the extraction of dye from $M$. pruriens using Box-Behnken method. The dye extracted under optimized conditions is shown in Figure 2.

\section{Analysis of Box-behnken design}

In this study, the Box- Behnken design is used in developing a model for the optimization of the extraction process with four process variables (temperature, time, feed to solvent ratio and size of the feed) at three levels. The experimental data's, which are obtained from 29 experiments and the predicted data, which is obtained from a response surface model, are compared as shown in Table 1. The significance and adequacy of the quadratic model were tested using Analysis of Variance (ANOVA) as shown in Table 2 .

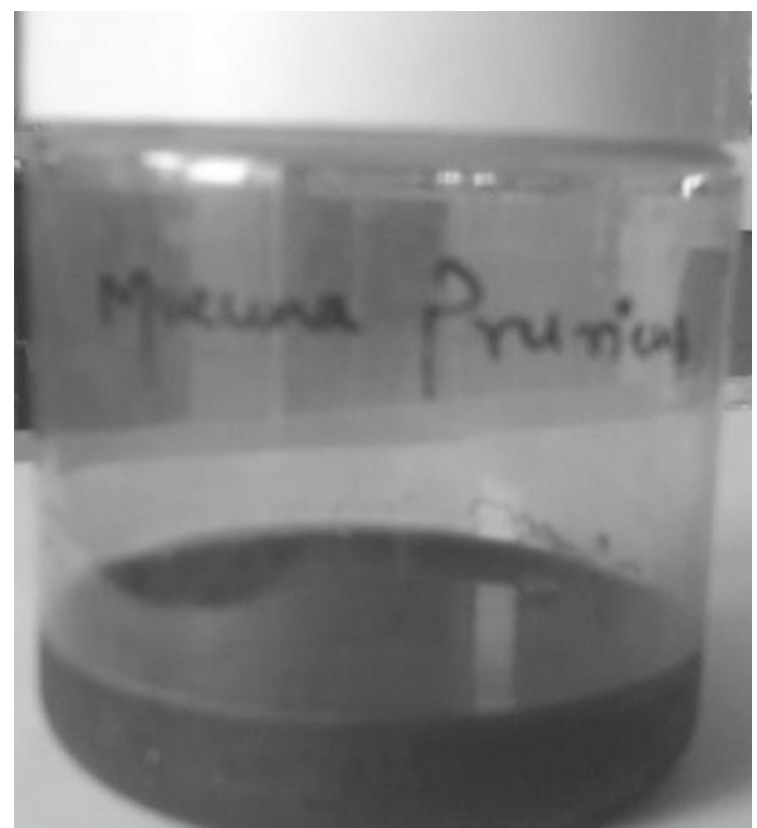

Figure 2. The photograph of the natural dye extract from Mucuna pruriens

\begin{tabular}{|c|c|c|c|c|c|}
\hline Source & Sum of Squares & $\begin{array}{l}\text { Degrees of } \\
\text { freedom }\end{array}$ & Mean square & F-value & $\begin{array}{l}\text { P-value } \\
\text { Prob }>F\end{array}$ \\
\hline Model & 1060.91 & 14 & 75.78 & 37.44 & $<0.0001$ \\
\hline A-Temperature & 374.08 & 1 & 374.08 & 184.84 & $<0.0001$ \\
\hline B-Time & 6.75 & 1 & 6.75 & 3.34 & 0.0892 \\
\hline C-Solvent to feed ratio & 14.08 & 1 & 14.08 & 6.96 & 0.0195 \\
\hline D-size & 6.75 & 1 & 6.75 & 3.34 & 0.0892 \\
\hline$A B$ & 49.00 & 1 & 49.00 & 24.21 & 0.0002 \\
\hline $\mathrm{AC}$ & 1.00 & 1 & 1.00 & 0.49 & 0.4936 \\
\hline$A D$ & 6.25 & 1 & 6.25 & 3.09 & 0.1007 \\
\hline $\mathrm{BC}$ & 0.25 & 1 & 0.25 & 0.12 & 0.7305 \\
\hline BD & 1.00 & 1 & 1.00 & 0.49 & 0.4936 \\
\hline$C D$ & 4.00 & 1 & 4.00 & 1.98 & 0.1816 \\
\hline$A^{2}$ & 510.91 & 1 & 510.91 & 252.45 & $<0.0001$ \\
\hline $\mathrm{B}^{2}$ & 154.16 & 1 & 154.16 & 76.17 & $<0.0001$ \\
\hline $\mathrm{C}^{2}$ & 63.34 & 1 & 63.34 & 31.30 & $<0.0001$ \\
\hline $\mathrm{D}^{2}$ & 85.24 & 1 & 85.24 & 42.12 & $<0.0001$ \\
\hline Residual & 28.33 & 14 & 2.02 & & \\
\hline Lack of Fit & 28.33 & 10 & 2.83 & & \\
\hline Pure Error & 0.000 & 4 & 0.000 & & \\
\hline Cor Total & 1089.24 & 28 & & & \\
\hline
\end{tabular}

$\mathrm{SD}=1.42 ;$ mean $=38.52 ;$ coefficient of variation $(\%)=3.69 ; \mathrm{R}$ square $=0.9740 ;$ adjusted $\mathrm{R}$ square $=0.9480 ;$ predicted $\mathrm{R}$ square $=0.8502 ;$ adequate precision $=21.854$ 
The interaction between input variables of Box Behnken model are expressed by a regression equation as follows:

$$
\begin{aligned}
\text { \% yield }= & +42.48+22.58 A+4.38 B+6.31 C+1.06 D \\
& -35.50 A^{2}-4.88 B^{2}-7.03 C^{2}-0.91 D^{2}-7.00 A B \\
& +1.50 A C+1.25 A D+0.38 B C-0.25 B D-0.75 C D
\end{aligned}
$$

ANOVA and F-test are carried out to analyze the fit of model and identify the influence of each factor on response. The Model F-value of 37.44 implies the model is significant. In this case $\mathrm{A}, \mathrm{C}, \mathrm{AB}, \mathrm{A}^{2}, \mathrm{~B}^{2}, \mathrm{C}^{2}, \mathrm{D}^{2}$ are significant model terms as the $p$ values lower than 0.05 indicate that the model and the terms are statistically significant ${ }^{16}$.The coefficient of determination $\left(\mathrm{R}^{2}\right)$ and adjusted $R^{2}$ values are used to calculate the adequacy and fitness of the model. The $\mathrm{R}^{2}$ value was found to be 0.9780 , which shows the compatibility of experimental data. The adjusted $R^{2}$ value rectifies the value of $R^{2}$ for the sample size and for the number of terms in the model and the adjusted $\mathrm{R}^{2}=0.9480$ value signifies a good correlation between the experimentally observed and the predicted values.

The "Pred R-Squared" of 0.8502 is in reasonable agreement with the "Adj R-Squared" of 0.9480; i.e. the difference is less than 0.2 . The low $\mathrm{p}$ value $(<0.0001)$ show that the model is significant and sufficient to explain the actual relationship between the factors and response.

The coefficient of variation (CV) indicates the deviation of experimental data from the predicted ones. Therefore, CV less than $10 \%$ is necessary for developing a good response model $^{17}$. From the tabulation, it can be observed that the value of $\mathrm{CV}$ is 3.69, indicating the precision of experimental data. "Adeq Precision" measures the signal to noise ratio. A ratio greater than 4 is desirable ${ }^{\mathbf{1 8}}$ and ratio of 21.854 indicates an adequate signal. This model can be used to navigate the design space.

Plot of actual versus predicted values in Figure 3 shows the comparison between each experimental values and predicted values of model and estimates the adequacy of model. As the data's are close to the straight line, it can be said that there is a good agreement between real experimental values and predicted model values.

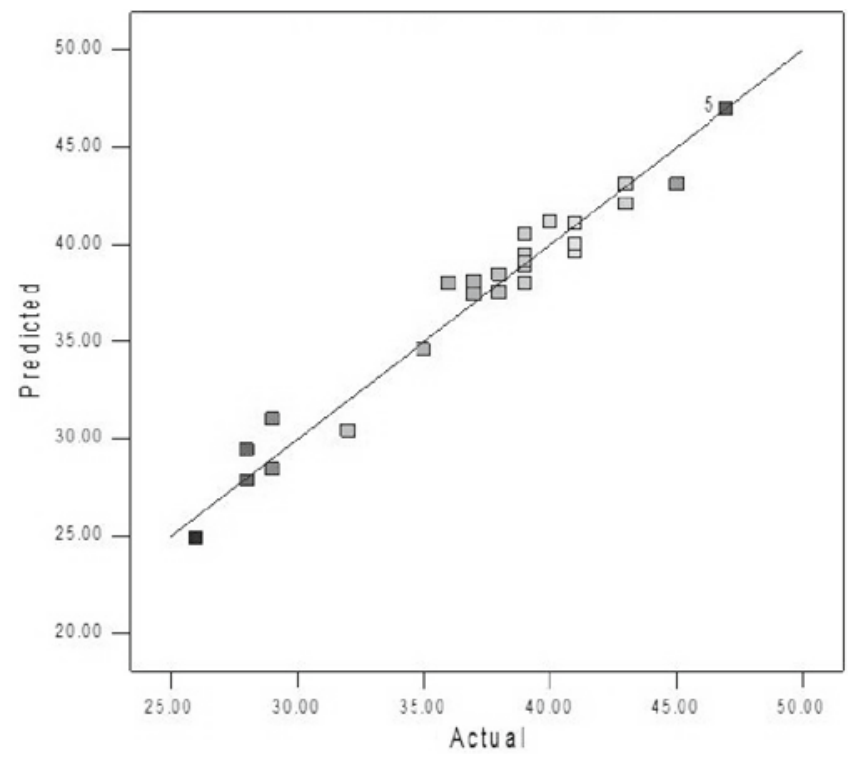

Figure 3. Predicted vs Actual plot for $\%$ yield

\section{Interaction between input and output parameters}

The response surface plots gives an idea of how the response changes up on changing two parameters at a time keeping other parameters as constant. To study the interactive effects of the chosen variables on yield of dye (\%), the three-dimensional profiles of models are shown in Figures 4-9. The elliptical nature of the contour plot shows the prominent interactions of variables. Percentage yield was found to increase up on increasing the temperature from 30 to $60^{\circ} \mathrm{C}$. Further increase in temperature after $60^{\circ} \mathrm{C}$ was found to decrease the $\%$ yield. This is because when the temperature is increased, density of the solvent changes which decreases the solubility of pigment in solvent and thereby decreasing the yield. Thus, optimal extraction temperature depends on the type of solvent chosen and their ratio used in the process. In addition, plant parts start to thermally degrade when the temperature is raised beyond a limiting point.

In the case of analyzing the effect of feed to solvent ratio on $\%$ yield, it almost showed a proportional increase in yield with increase in ratio of the solvent to feed from 3:1 till 5:1 in the ranges studied. Beyond this ratio, no further increase in yield was noticed. The effect of extraction time on yield can be correlated with the higher contact time of solvent with the powdered sample, which has extracted more pigment in to the solution,

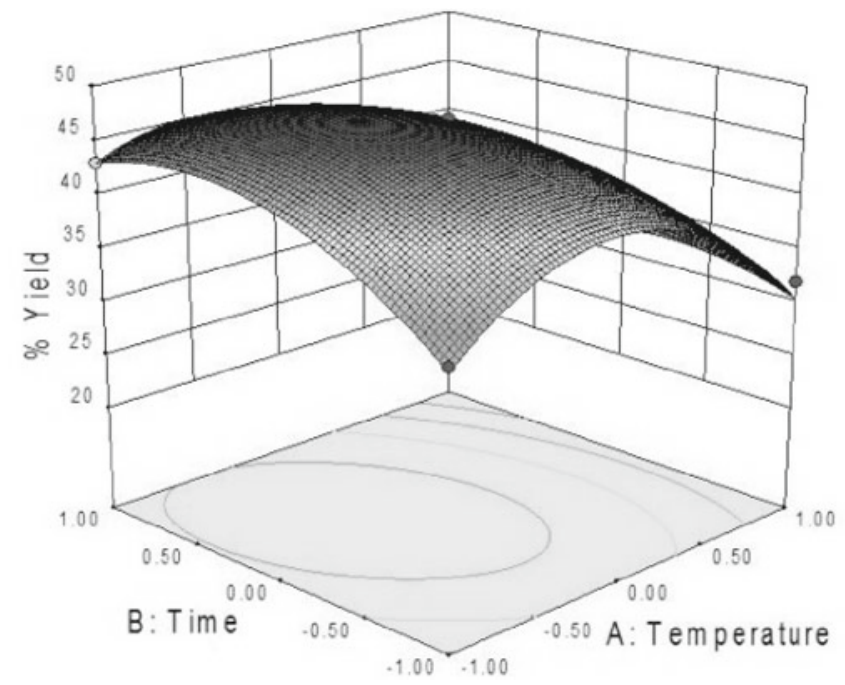

Figure 4. 3D Surface plot of interaction between temperature and extraction time on $\%$ yield of dye

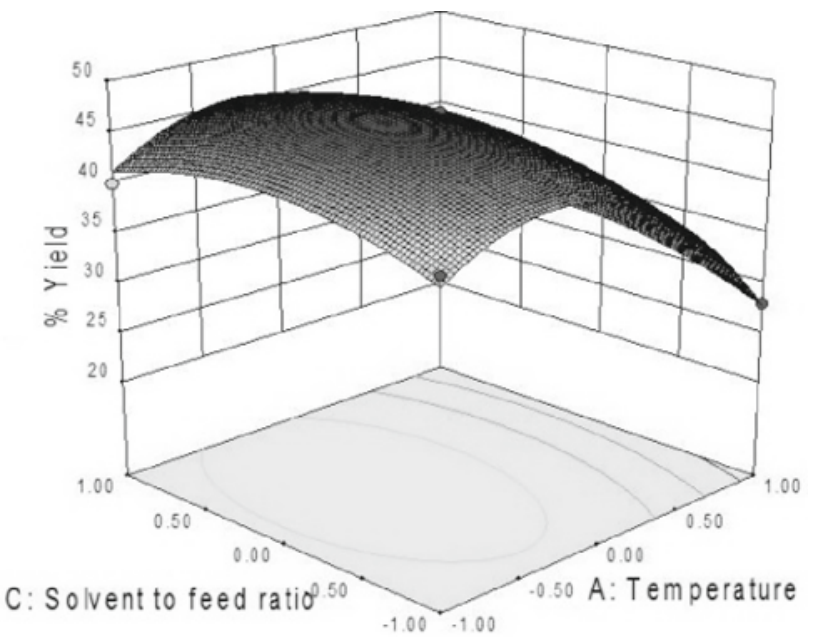

Figure 5. 3D Surface plot of interaction between Temperature and Solvent to feed ratio on $\%$ yield of dye 


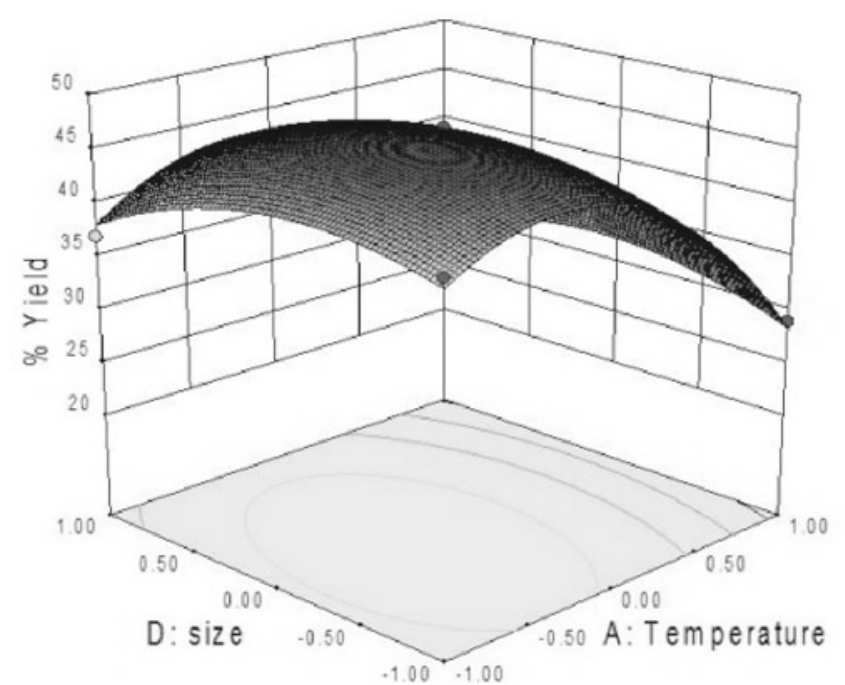

Figure 6. 3D Surface plot of interaction between Temperature and feed size on $\%$ yield of dye

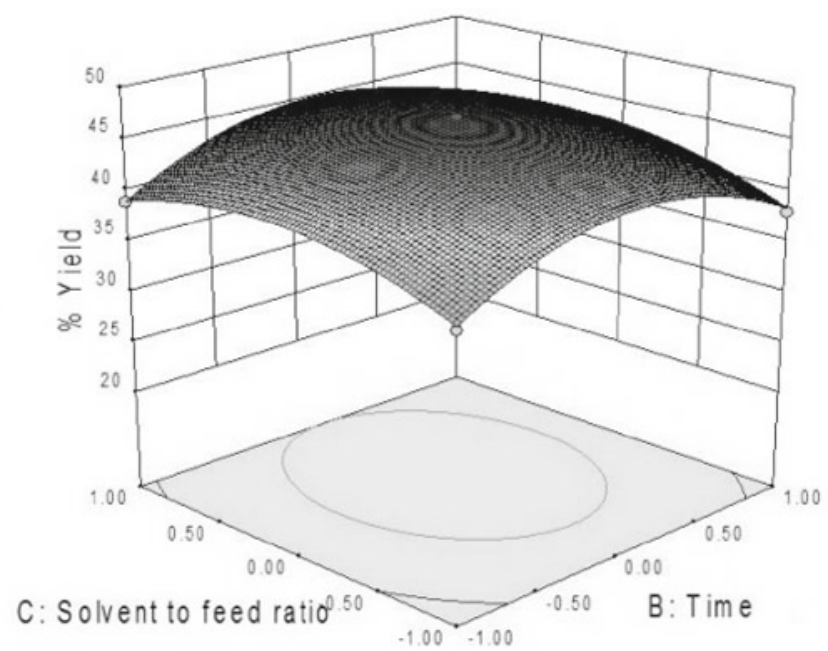

Figure 7. 3D Surface plot of interaction between Extraction time and Solvent to feed ratio on $\%$ yield of dye

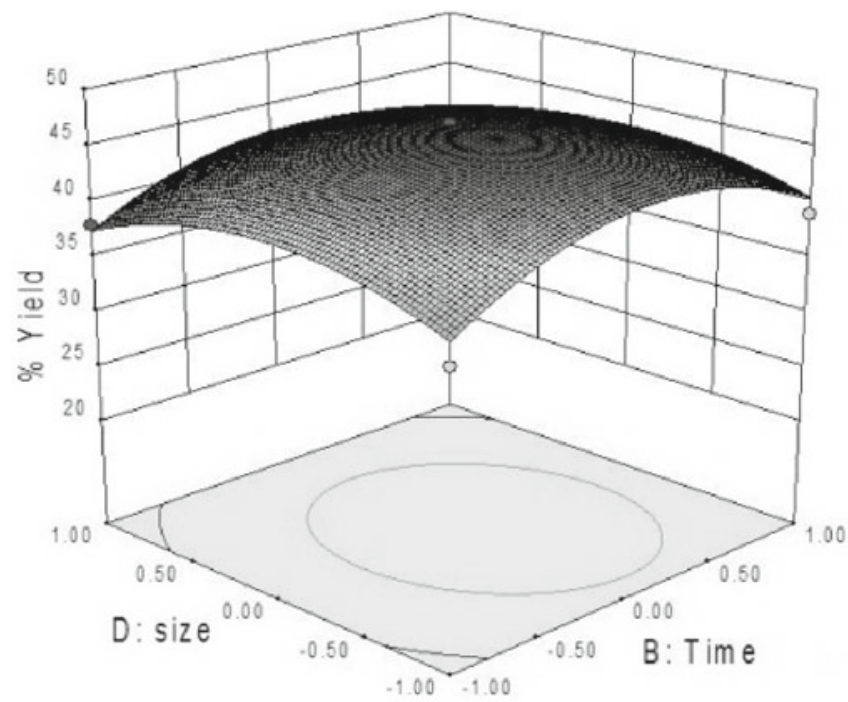

Figure 8. 3D Surface plot of interaction between Extraction time and Size on $\%$ yield of dye

but further increase in time after 60 min resulted in decrease in yield, which might be due to decomposition of colouring matter at higher temperature with more contact time. A maximum yield of $47 \%$ was obtained for a particle size of $0.75 \mathrm{~mm}$ as this size gives more

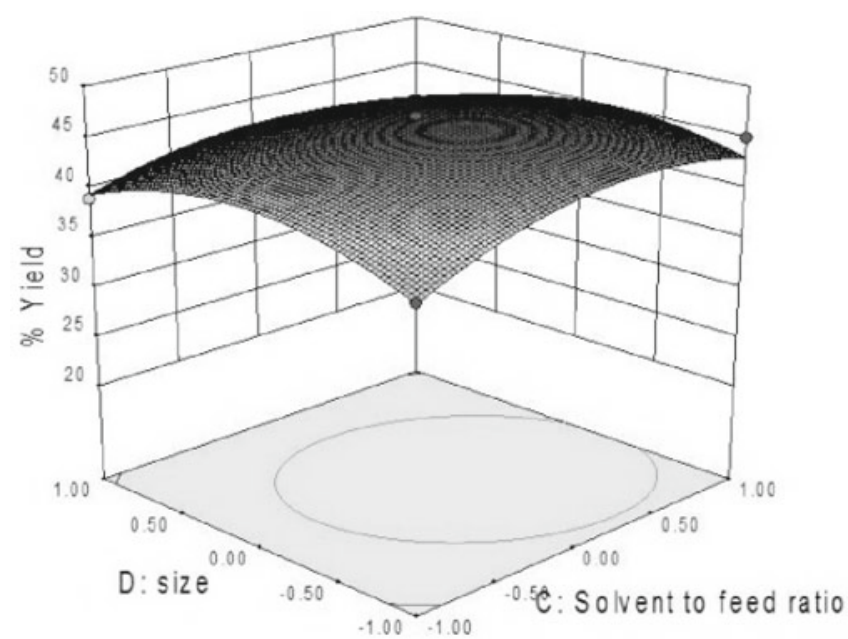

Figure 9. 3D surface plot of interaction between Solvent to feed ratio and size on $\%$ yield of dye

surface area and thereby assist the rate of extraction. By carrying out optimization, the following results are obtained as shown in Table 3.

Table 3. Optimization of input parameters

\begin{tabular}{|l|c|}
\hline Variables (unit) & Optimized values \\
\hline Temperature, ${ }^{\circ} \mathrm{C}$ & $60^{\circ} \mathrm{C}$ \\
\hline Time, $\mathrm{min}$ & $60 \mathrm{~min}$ \\
\hline Solvent to feed ratio & $5: 1$ \\
\hline Feed size, $\mathrm{mm}$ & $0.75 \mathrm{~mm}$ \\
\hline
\end{tabular}

\section{Dyeing of leather}

The presence of unexhausted synthetic dye in the effluent poses environmental hazard. In contrast, natural dyes are biodegradable and environment friendly and there is no environmental risk involved in spent dye liquor (from natural source) unlike the case of synthetic dyes. After optimization, the leather samples were dyed with $M$. pruriens under optimum conditions as shown in Figure 10 and 11.

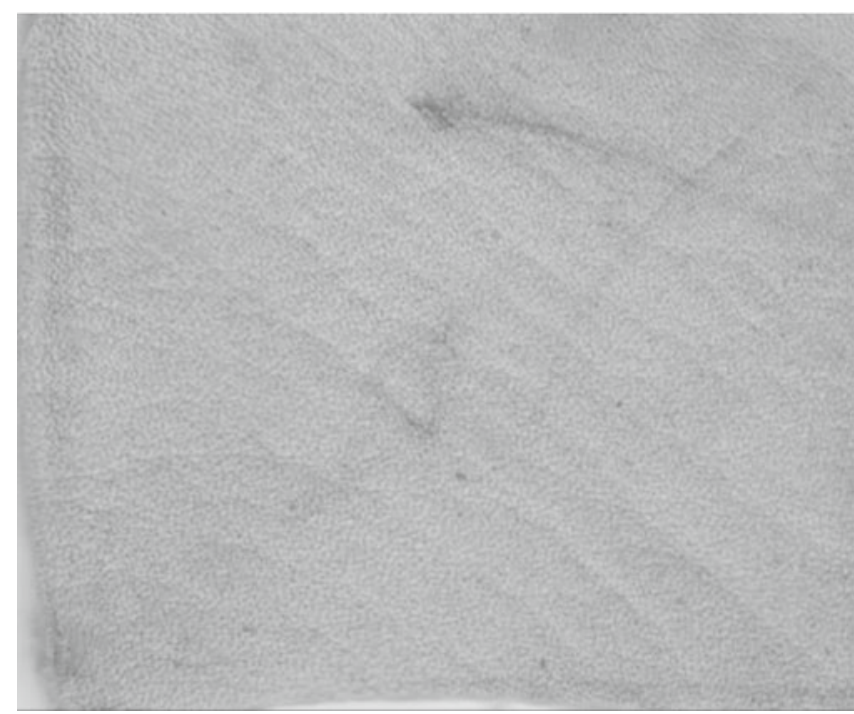

Figure 10. Chrome tanned leather before dyeing

\section{Analysis of Colour}

The colour value of the leather dyed with $M$. pruriens was analyzed by reflectance measurement and the colour values are shown in Table 4. Increase in the value of ' $a$ ' 
Table 4. Colour value table

\begin{tabular}{|l|c|c|c|c|c|c|}
\hline S.No. & Source name & 'L' & 'a' & 'b' & 'c' $\mathrm{h}^{\prime}$ \\
\hline 1 & Leather (Before dyeing) & 66.80 & 5.402 & 21.562 & 27.861 & 76.283 \\
\hline 2 & Leather after dyeing with Mucuna pruriens & 69.064 & 9.757 & 12.721 & 13.628 & 68.975 \\
\hline
\end{tabular}

and decrease in the value of ' $b$ ' shows an enhancement in red and blue shade of the leather dyed with $M$. pruriens.

\section{Assessment of colour and properties of leathers}

Visual assessment of leather samples (before \& after dyeing) for colour change, uniformity, depth of shade, intensity and general appearance was carried out by average value of hand evaluation by three experts. The strength properties of dyed leather are tested as per Indian standards (IS 576, 1975) and are shown in Table 5.

Table 5. Visual assessment of dyed leather

\begin{tabular}{|c|c|c|c|c|c|c|c|}
\hline S.No & Sample of Leather & Colour & $\begin{array}{l}\text { Uniformity } \\
\text { of shade }\end{array}$ & General Appearance & Softness & Toughness & Fullness \\
\hline 1 & Leather before dyeing & 8 & 6 & 7.5 & 6 & 6 & 8.5 \\
\hline 2 & Leather after dyeing with Mucuna pruriens & 7 & 6.5 & 6.5 & 6 & 6 & 8 \\
\hline
\end{tabular}

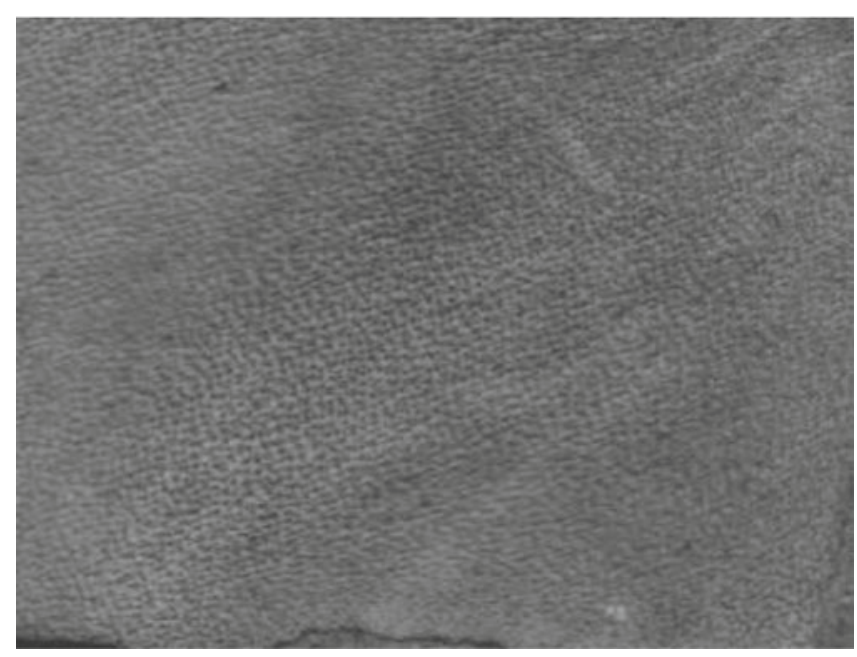

Figure 11. Chrome tanned leather after dyeing with Mucuna pruriens

It can be seen that the dyed pigments did not affect the characteristics of leather except the softness property, which necessitates a change in percentage of fat liquor to be used in the experiment.

\section{Estimation of fastness property}

The change in colour of the leather samples under suitable illumination was analyzed as per IS: 2484:1985. The dyed leather showed a fair light fastness as rated 3 on grey scale.

\section{CONCLUSION}

Box Behnken method was successfully employed for optimizing the four factors (temperature, time, feed to solvent ratio and size) which influenced the extraction of pigment from $M$. pruriens. The interaction between these variables and their effect on response (\% yield) are studied using response surface plots. The optimized parameters for extraction are as follows: extraction temperature $-60^{\circ} \mathrm{C}$, extraction time $-60 \mathrm{~min}$, feed to solvent ratio $-1: 5$ and particle size $-0.75 \mathrm{~mm}$, respectively. The ANOVA showed a high coefficient of determination value $\mathrm{R}^{2}=0.9740$ ensuring a good fit of model with the experimental data. The colour value, strength and fastness properties of the dyed leather was found to be satisfactory. This study clearly demonstrates that the natural dyes can be used for dyeing of leather and by suitable mordant treatment, many fashion shades can be achieved and thereby environmentally harmful synthetic dyes can be avoided.

\section{LITERATURE CITED}

1. Neelwarne, B. \& Halagur, S.B., Red Beet: An Overview, in Neelwarne, Bhagyalakshmi (Ed.), Food and Pharmaceutical Applications, pp 1-43, Springer New York Heidelberg Dordrecht London, 2012.

2. Khan, A.A., Iqbal, N., Adeel, S., Azeem, M., Batool, F. \& Bhatti, I.A. (2014). Extraction of natural dye from red calico leaves: Gamma ray assisted improvements in colour strength and fastness properties. Dyes Pigments.103, 50-54. DOI: 10.1016/j. dyepig.2013.11.024.

3. Leitner, P., Fitz-Binder, C., Mahmud-Ali, A. \& Bechtold, T. (2012). Production of a concentrated natural dye from Canadian Goldenrod (Solidago canadensis) extracts. Dyes Pigments. 93 (1-3), 1416-1421. DOI: 10.1016/j.dyepig.2011.10.008

4. Velmurugan, P., Kamala-KannanS., Balachandar, V., Lakshmanaperumalsamy, L., Chan Chae, J. \& Taek Oh, B. (2010). Natural pigment extraction from five filamentous fungi for industrial applications and dyeing of leather. CarbohydPolym. 79 (2), 262-268. DOI: 10.1016/j.carbpol.2009.07.058.

5. Rai, H.S., Bhattacharyya, M.S., Singh, J., Bansal, T.K., Vats, P. \& Banerjee, U.C. (2005).Removal of dyes from the effluent of textile and dyestuff manufacturing industry: a review of emerging techniques with reference to biological treatment. Crit. Rev. Environ. Sci. Technol. 35 (3), 219-238. DOI: $10.1080 / 10643380590917932$.

6. Ahlstrom, L., Eskilsson, C.S. \& Björklund, E. (2005). Determination of banned azo dyes in consumer goods. Trends Anal. Chem. 24 (1), 49-56. DOI: 10.1016/j.trac.2004.09.004.

7. Alves de Lima, R.O., Paula, B.A., Maria, F.S.D., Maria, R.C., Danielle, D.P.O. \& Gisela, D.R.U. (2007). Mutagenic and carcinogenic potential of a textile azo dye processing effluent that impacts a drinking water source. Mutat. Res. 626, 53-60. DOI: 10.1016/j.mrgentox.2006.08.002.

8. Osman, M.Y., Sharaf, I.A., Osman, H.M., El-Khouly, Z.A. \& Ahmed, E.I. (2004). Synthetic organic food colouring agents and their degraded products: effects on human and rat cholinesterases. Br. J. Biomed. Sci. 61(3), 128-32. PMID: 15462257. 9. Chatterjee, S., Chatterjee, S., Bishnu, P., Chatterjee \& Guha, A.K. (2007).Adsorptive removal of congo red, a carcinogenic textile dye by chitosan hydrobeads: Binding mechanism, equilibrium and kinetics. Physicochem. Eng. Aspects. 299 (1-3), 146-152. DOI: 10.1016/j.colsurfa.2006.11.036. 
10. Sivakumar, V., Anna, J.L., Vijayeeswarri, J. \& Swaminathan, G. ultrasonsonochem. 16(6): 782-9. DOI: 10.1016/j. ultsonch.2009.03.009.

11. Myers, R.H., Montgomery. D.C. \& Anderson-Cook, C.M. (2009). Response surface methodology: Process and product optimization using designed experiments (Third Ed.), John Wiley \& Sons, New Jersey.

12. Rekaby, M., Salem, A.A. \& Nassar, S.H. (2009, August). Eco-friendly printing of natural fabrics using natural dyes from alkanet and rhubarb. J. Text. Inst. 100(6), 486-495. Retrieved October $25^{\text {th }}, 2007$, from the Journal of the Textile Institute on the World Wide Web: http://www.tandfonline.com/ DOI: $10.1080 / 00405000801962177$.

13. Bezerra, M.A., Santelli, R.E., Oliveira, E.P., Villar, L.S. \& Escaleira, L.A. (2008). Response surface methodology (RSM) as a tool for optimization in analytical chemistry. Talanta. 76 (5), 965-977. DOI: 10.1016/j.talanta.2008.05.019.

14. Ferreira, S.L.C., Bruns, R.E. \& Ferreira, H.S. (2007). Box-Behnken design: An alternative for the optimization of analytical methods. Anal. Chim. Acta. 597 (2), 179-186. DOI: 10.1016/j.aca.2007.07.011.

15. Kamel, M.M., El-Zawahry, M.M., Ahmed, N.S.E. \& Abdelghaffar, F. (2011). Ultrasonic dyeing of cationized cotton fabric with natural dye. Part 2: Cationization of cotton using Quat 188. Ultrason. Sonochem. 34(3), 1410-1417. DOI: 10.1016/j. indcrop.2011.04.011.

16. Balasubramanian, A. \& Venkatesan, S. (2012). Optimization of Removal of Phenol from Aqueous Solution by Ionic Liquid-Based Emulsion Liquid Membrane Using Response Surface Methodology. Clean - Soil, Air, Water 42 (1), 64-70. DOI: $10.1002 /$ clen.201200168

17. Segurola, J., Allen, N.S., Edge, M., Mahon, A.M. (1999). Design of eutectic photoinitiator blends for UV/visible curable acrylated printing inks and coatings. Prog. Org. Coat. 37(1-2), 23-37. DOI: 10.1016/S0300-9440(99)00052-1.

18. Maran, J.P. \& Manikandan, S. Response surface modeling and optimization of process parameters for aqueous extraction of pigments from prickly pear (Opuntia ficus-indica) fruit (2012). Dyes Pigments. 95(3), 465-472. DOI: 10.1016/j. dyepig.2012.06.007.

19. Beg, Q.K., Sahai, V. \& Gupta, R. (2003). Statistical media optimization and alkaline protease production from Bacillus mojavensis in a bioreactor. ProcessBiochem. 39 (2), 203-209. DOI: 10.1016/S0032-9592(03)00064-5. 